\title{
Lack of phonotactic preferences of female frogs and its consequences for signal evolution
}

\author{
Nelson A. Velásquez ${ }^{a, b}, *$, Jose Luis Valdés ${ }^{a}$, Rodrigo A. Vásquez ${ }^{c}$, Mario Penna ${ }^{a}$ \\ a Programa de Fisiología y Biofísica, ICBM, Facultad de Medicina, Universidad de Chile, Independencia 1027, Santiago, Chile \\ b Facultad de Ciencias Básicas, Universidad Católica del Maule, San Miguel 3605, 3480112 Talca, Chile \\ ${ }^{\mathrm{c}}$ Instituto de Ecología y Biodiversidad, Universidad de Chile, Las Palmeras 3425, Santiago, Chile
}

\section{A R T I C L E I N F O}

\section{Article history:}

Received 19 January 2015

Received in revised form 1 June 2015

Accepted 1 June 2015

Available online 4 June 2015

\section{Keywords:}

Sexual selection

Geographic variation

Female choice

\begin{abstract}
A B S T R A C T
Sexual selection is one of the main evolutionary forces that drive signal evolution. In previous studies, we have found out that males of Pleurodema thaul, a frog with an extensive latitudinal distribution in Chile, emits advertisement calls that show remarkable variation among populations. In addition, this variation is related to intense inter-male acoustic competition (intra-sexual selection) occurring within each population. However, the extent to which female preferences contribute to the signal divergence observed is unclear. To study the responsiveness of females in each population, we stimulated females with synthetic calls designed with the acoustic structure of their own population and subsequently responsive females were subjected to a two-choice experiment, where they were stimulated with synthetic calls of their own population versus a call of a foreign population. Females do not show phonotactic preferences for calls of their own or foreign populations as measured with both linear and circular variables. The lack of phonotactic preferences suggests an absence of participation of inter-sexual selection processes in the divergence of the acoustic signals of $P$. thaul, highlighting the importance of intra-sexual selection for the evolution of these signals. These results concur with studies in other vertebrates emphasizing the relevance of interactions among males for the evolution of acoustic communication systems.
\end{abstract}

(C) 2015 Published by Elsevier B.V.

\section{Introduction}

Sexual selection plays a fundamental role in the evolution of sender and receiver features in communicating organisms. According to this theory, males produce conspicuous signals by means of which they compete for access to females (intra-sexual selection), and/or females exert preferences for these displays resulting in mate choice (inter-sexual selection) (Darwin, 1871; Andersson, 1994; Searcy and Nowicki, 2009). When sexual selection operates in disjunct populations of a same species, reproductive isolation and consequent evolutionary divergence and speciation are likely outcomes (Coyne and Orr, 2004). These selective mechanisms may generate geographic variation of the signals emitted by senders and/or the responses displayed by receivers, affecting directly the appropriate matching between these two components and potentially altering conspecific recognition and breeding (Wilczynski and Ryan, 1999). The study of geographic variation in communication

\footnotetext{
* Corresponding author at: Facultad de Ciencias Básicas, Universidad Católica del Maule, San Miguel 3605, 3480112, Talca, Chile. Tel.: +56 712203370.

E-mail address: nvelasquez@ucm.cl (N.A. Velásquez).
}

systems can therefore shed light on the evolutionary processes promoting the divergence between populations.

Anurans use acoustic communication extensively during their breeding seasons. Males produce advertisement calls that attract females and promote the establishment of territories (Gerhardt and Huber, 2002). Geographic variation of these signals has been reported to occur in various cases (e.g., Nevo and Capranica, 1985; Pröhl et al., 2006, 2007; Wilczynski and Ryan, 1999; Velásquez et al., 2013) and has been attributed to different factors such as environmental conditions affecting signal propagation (Wilczynski and Ryan, 1999), genetic or geographic distances (Bernal et al., 2005; Pröhl et al., 2006, 2007; Velásquez et al., 2013), and/or sexual selection processes (Boul et al., 2007; Velásquez et al., 2014). However, few studies on the geographic variation of female preferences in response to male calls from populations of different geographical origin have been carried out. Pröhl et al. (2006) reported discrimination experiments (i.e., two-choice) showing female preferences in Engystomops (=Physalaemus) pustulosus for male calls from their own population relative to those of foreign populations. In this case, inter-sexual selection would lead to stabilizing selection would contribute to pre-zygotic barrier preventing hybridization and males of about average size are preferred. In contrast, Ryan 
Table 1

Values of the acoustic parameters used to build the synthetic calls used in the phonotaxis experiments.

\begin{tabular}{|c|c|c|c|c|c|c|}
\hline Acoustic parameter & Totoral & Los Maitenes & Osorno & $\mathrm{Om}(\mathrm{T})$ & $\mathrm{Om}(\mathrm{LM})^{\mathrm{a}}$ & $\mathrm{Om}(\mathrm{O})^{\mathrm{a}}$ \\
\hline Call duration (s) & 3.8 & 4.3 & 1.8 & 3.7 & 4.2 & 4.2 \\
\hline Number of pulses per call & 29 & 39 & 14 & 29 & 33 & 33 \\
\hline Pulse duration (ms) & 57 & 58 & 65 & 65 & 65 & 65 \\
\hline Interpulse interval (ms) & 75 & 53 & 65 & 64 & 64 & 64 \\
\hline Modulation depth (\%) & 91 & 88 & 58 & 58 & 58 & 58 \\
\hline Dominant frequency $(\mathrm{Hz})$ & 1870 & 2140 & 1790 & 1790 & 1790 & 1790 \\
\hline Rise time functions & $\begin{array}{l}f(t)=101.42-59.991 \\
\exp \left(-2.1926^{*} t\right)\end{array}$ & $\begin{array}{l}\mathrm{f}(\mathrm{t})=101.87-54.358 \\
\exp \left(-2.3209^{*} \mathrm{t}\right)\end{array}$ & $\begin{array}{l}f(t)=98.915-70.592 \\
\exp \left(-3.0621^{*} t\right)\end{array}$ & $\begin{array}{l}\mathrm{f}(\mathrm{t})=98.915-70.592 \\
\exp \left(-3.0621^{*} \mathrm{t}\right)\end{array}$ & $\begin{array}{l}\mathrm{f}(\mathrm{t})=98.915-70.592 \\
{ }^{*} \exp \left(-3.0621^{*} \mathrm{t}\right)\end{array}$ & $\begin{array}{l}f(t)=98.915-70.592 \\
\exp \left(-3.0621^{*} t\right)\end{array}$ \\
\hline
\end{tabular}

* $\mathrm{Om}(\mathrm{LM})$ and $\mathrm{Om}(\mathrm{O})$ have the same structure. See the text for details.

et al. (1992) reported discrimination experiments with females of Acris crepitans showing strong preferences for calls with low frequency contents relative to population averages. These results have been mostly interpreted in terms of the sensory exploitation model, implying that receivers have pre-existing biases in their sensory systems that are subsequently used advantageously by senders (see Endler and Basolo, 1998 and Ryan, 1998 for general discussions on receiver biases and sensory exploitation). In these conditions, larger-than-average males producing relatively low frequency calls are favored by inter-sexual selection.

Pleurodema thaul (Leiuperidae) is an anuran broadly distributed in Chile, ranging from the Atacama Desert $\left(27^{\circ} 06^{\prime} \mathrm{S}, 69^{\circ} 53^{\prime} \mathrm{W}\right)$ to the Patagonian region $\left(45^{\circ} 24^{\prime} \mathrm{S}, 72^{\circ} 42^{\prime} \mathrm{W}\right)$; (Correa et al., 2007; Veloso, 2006). This species has a prolonged breeding season, from May to December. During this period, males congregate in chorusing assemblages, producing advertisement calls while perching on low vegetation or floating on the water surface of pools and slow-flowing streams. A recent study of geographic variation of the advertisement calls of this species has revealed the existence of three bioacoustic groups, differing in the structure of both temporal and spectral components, corresponding to northern, central and southern populations (Velásquez et al., 2013) (Velásquez, 2014). In addition, a study of evoked vocal responses (i.e., vocal responses that are elicited by a stimulus and do not correspond to spontaneous vocal activity) revealed that males of this species exhibit different vocal activity when confronted with local or foreign stimuli, implying intra-sexual selection in the origin of advertisement call divergence (Velásquez et al., 2014).

In the current study, we examine the phonotactic preferences of female frogs $P$. thaul of different geographic origin for signals having local and foreign features, in order to explore the extent to which inter-sexual selection is involved in the generation of the observed geographic variation in the advertisement calls of this species. Preferences of this kind would denote the action of past selective pressures originating the contemporary divergence patterns observed. The comparison of the status of variation in signals and preferences is meant to provide evidence on the precedence order of the evolutionary divergence of components of the sound communication system along the geographical distribution of this species.

\section{Methods}

\subsection{Subjects}

We conducted phonotaxis experiments with females from three localities within the distribution range of $P$. thaul. The tests were conducted in the localities from which the frogs were native (Totoral, northern population: $27^{\circ} 54^{\prime} \mathrm{S}, 70^{\circ} 56^{\prime} \mathrm{W}, 136 \mathrm{~m}$ a.s.l.; Los Maitenes, central population: $34^{\circ} 41^{\prime} \mathrm{S}, 71^{\circ} 26^{\prime} \mathrm{W}, 140 \mathrm{~m}$ a.s.l. and Osorno, southern population: $40^{\circ} 35^{\prime} \mathrm{S}, 73^{\circ} 03^{\prime} \mathrm{W}, 70 \mathrm{~m}$ a.s.l.). The experiments in Totoral and Los Maitenes were conducted during
September and October 2009 and in Osorno during September 2010. In each population, females were captured during daytime, under stones or low vegetation in the vicinity of breeding sites: pools or slow flowing creeks. The subjects were maintained in individual containers until tests were carried out at nighttime, within $12 \mathrm{~h}$ of capture.

\subsection{Synthetic stimuli}

The advertisement call of $P$. thaul has a remarkable variation along the latitudinal range of the species (Velásquez et al., 2013). We used the analysis carried out in that previous study, which corrected the acoustical parameters for the morphological and environmental parameters measured in each population to build the synthetic stimuli (see Velásquez et al., 2013 for details on the analysis of the advertisement calls used for the synthesis of the stimuli used in the current study). Briefly, in Velásquez et al. (2013) advertisement calls of 27, 17 and 23 males from the localities of Totoral, Los Maitenes and Osorno, respectively, were recorded. Based on the mean values of the acoustic parameters, we built standard synthetic calls for each population, imitating the natural calls emitted by local males, using Adobe Audition 3.0. The acoustic parameters to build the Standard synthetic calls for Totoral, Los Maitenes and Osorno are listed in Table 1. In addition, the gradual amplitude increase of the 10 first pulses was modeled with different rise curves for the standard synthetic calls of each population (Table 1, Fig. 1a). These stimuli were also used to explore the geographic variation of the evoked vocal responses in males of this species in a subsequent study (Velásquez et al., 2014). Because the standard stimulus of Osorno had a short call duration and a small number of pulses relative to the synthetic calls of the other two populations, additional stimuli were built to compensate for the low values of these variables of stimulus and for potential biases produced by call duration and number of pulses on females preferences. Thus, in addition to the standard synthetic calls of each population, we built three different synthetic calls having the same pulse duration, modulation depth and dominant frequency as the standard synthetic call of Osorno, but having the approximate call duration, number of pulses and inter-pulse interval duration of the standard synthetic call of each population studied (Osorno modified synthetic calls, Om). For the tests with females from Totoral and Los Maitenes, these calls had durations of 3.8 and $4.2 \mathrm{~s}$, and number of pulses of 29 and 33 pulses, respectively. Similarly, an Osorno modified call was synthesized for tests with females from the Osorno population, and in this case the characteristics of the stimulus having the longer duration and larger number of pulses (e.g., Los Maitenes: $4.2 \mathrm{~s}$ and 33 pulses, respectively) were chosen. These stimuli are shown in Fig. 1 and the acoustic parameters used to build them are also summarized in the Table 1 . These sounds were saved as WAV files $(44.1-\mathrm{kHz}$ sampling rate, 16 -bit resolution) and used to generate the stimulation schedules employed in the control and two-choice experiments. 
(A)

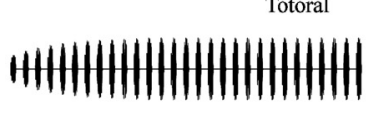

$$
\begin{aligned}
& \text { н Н|||||||||||||||||||||||||||| }
\end{aligned}
$$

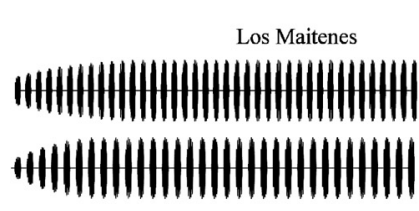

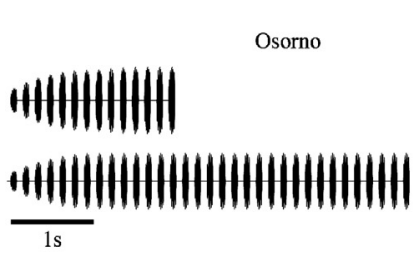

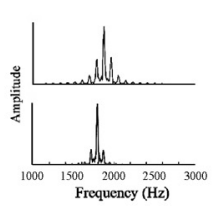
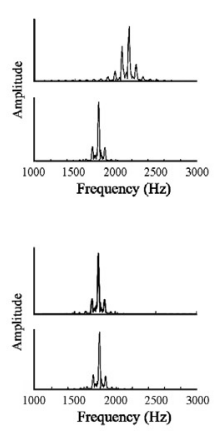

(B)

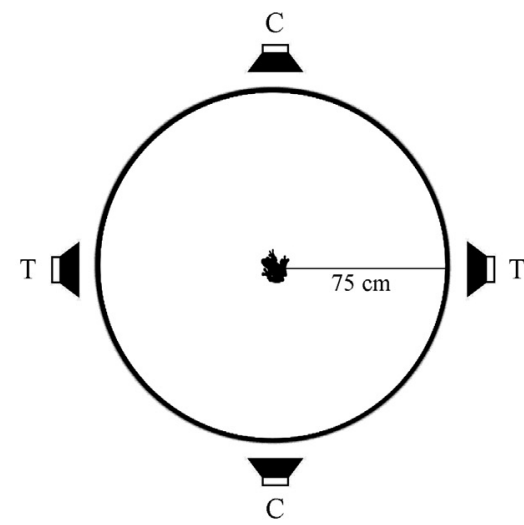

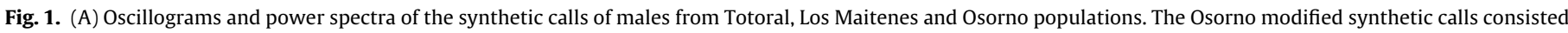

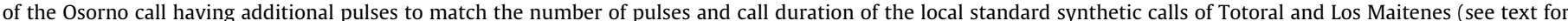

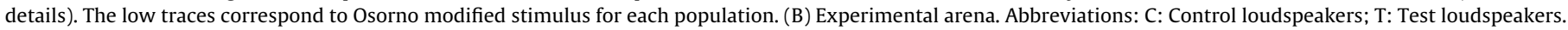

\subsection{Experimental settings}

The experimental arena was enclosed by two circular $150-\mathrm{cm}$ diameter aluminum frames and separated by vertical $25-\mathrm{cm}$ height aluminum bars. The inner wall of this structure was covered with an acoustic-transparent black plastic mesh. This frame stood on a linoleum carpet over which the experimental subjects walked during the phonotaxis experiments. Four loudspeakers (Versatec, $10-\mathrm{cm}$ diameter) were placed close to the external arena wall at $0,90,180$ and $270^{\circ}$. A foam wall of $50 \mathrm{~cm}$ height surrounded this custom-built experimental setting, to minimize reverberations. Two loudspeakers placed at $180^{\circ}$ from each other were used in the control experiment $(\mathrm{C})$ and the other two in two-choice experiments (T) (Fig. 1b). A fifth loudspeaker (Altec Lansing, Orbit M, 4,5-cm diameter) was placed $1 \mathrm{~m}$ above the center of the arena to emit at low level a continuous chorus noise recorded at the population of origin of the subjects. Chorus noises were presented to the subjects of Totoral and Osorno population. At these localities we recorded noise produced by dense choruses with a directional microphone (Sennheiser ME 66, Electronic GmbH \& Co., KG, Wedemark, Germany) placed at a minimum distance of $5 \mathrm{~m}$ from the nearest individual and a Tascam HD-P2 digital recorder (Montebello, CA, USA). The microphone was positioned at about $5 \mathrm{~m}$ from the nearest individual in order to have a chorus recording with a continuous structure to be employed to introduce the subjects to the settings of the phonotaxis experiments (see below). These sounds also were acquired at $44.1-\mathrm{kHz}$ sampling rate and 16 -bit resolution. At the study area in the population of Los Maitenes in central Chile, no dense choruses occurred, therefore, individuals from this population were not exposed to this sound.

\subsection{Control experiments}

Control experiments were carried out to test female receptivity to the local standard synthetic call. A female was placed at the center of the arena, restrained inside an inverted $15-\mathrm{cm}$ diameter plastic mesh strainer during $1 \mathrm{~min}$. During this time interval a chorus noise recorded at the local study site was played back from a third generation Ipod Nano (Apple Inc., Cupertino, CA, USA), the level adjusted to obtain $60 \mathrm{~dB}$ RMS SPL at the center of the arena and delivered from the chorus noise loudspeaker. Subsequently, the chorus noise was turned off and the local standard call was presented via one of the two control loudspeakers during $1 \mathrm{~min}$. Then, the inverted strainer was carefully removed to set the subject free. We considered that a positive response occurred if the subject came into contact with the arena wall, at least within $25^{\circ}$ on each side of the control loudspeaker through which the stimulus was emitted. We considered that the subject did not respond (No response) if after $5 \mathrm{~min}$ from the removal of the inverted strainer the female remained at the center of arena. A No response was also considered to occur if the female remained still for longer than 2 min at any position after leaving the center of the arena, or if it did not reach the response criterion within $15 \mathrm{~min}$. Only females who showed positive responses in the control experiment were subjected to subsequent two-choice experiments.

At each study site, the stimulus used in the control experiment was the local standard synthetic call. Repetitions of this stimulus separated by inter-stimuli intervals doubling the stimulus duration were presented. This interval was chosen because it is effective for prolonged stimulation of vocal responses of males of this species (Penna et al., 2008; Velásquez et al., 2014). Stimuli were played back with a third generation Ipod Nano (Apple Inc., Cupertino, CA, USA), passed through a two-channel impedance-matched operational amplifier and one attenuator (Hewlett-Packard 355C/D). The output signal was amplified (Alpine 3540) and broadcast via a control loudspeaker. The intensity of the synthetic call was adjusted to $70 \mathrm{~dB}$ RMS SPL before starting the experiment, by placing the microphone of a sound-level meter (Brüel \& Kjaer 2238; Brüel \& Kjaer Instruments, Inc., Boston, MA, USA) at the center of experimental arena. We used this level because it is about the average intensity of the advertisement calls of nearest neighbors of this species in breeding aggregations (Penna and Solís, 1998), and was the level used for previous studies on male evoked vocal responses with this species (Penna et al., 2008; Velásquez et al., 2014). Although this level is lower than the SPLs of the advertisement calls at $75 \mathrm{~cm}$ (the radius of the experimental arena) it is probably similar to the levels at which females are when they arrive in a natural chorusing aggregation. 

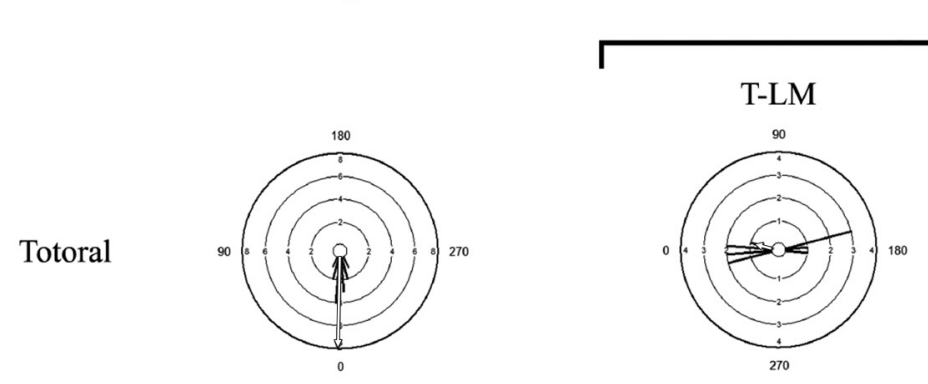

1
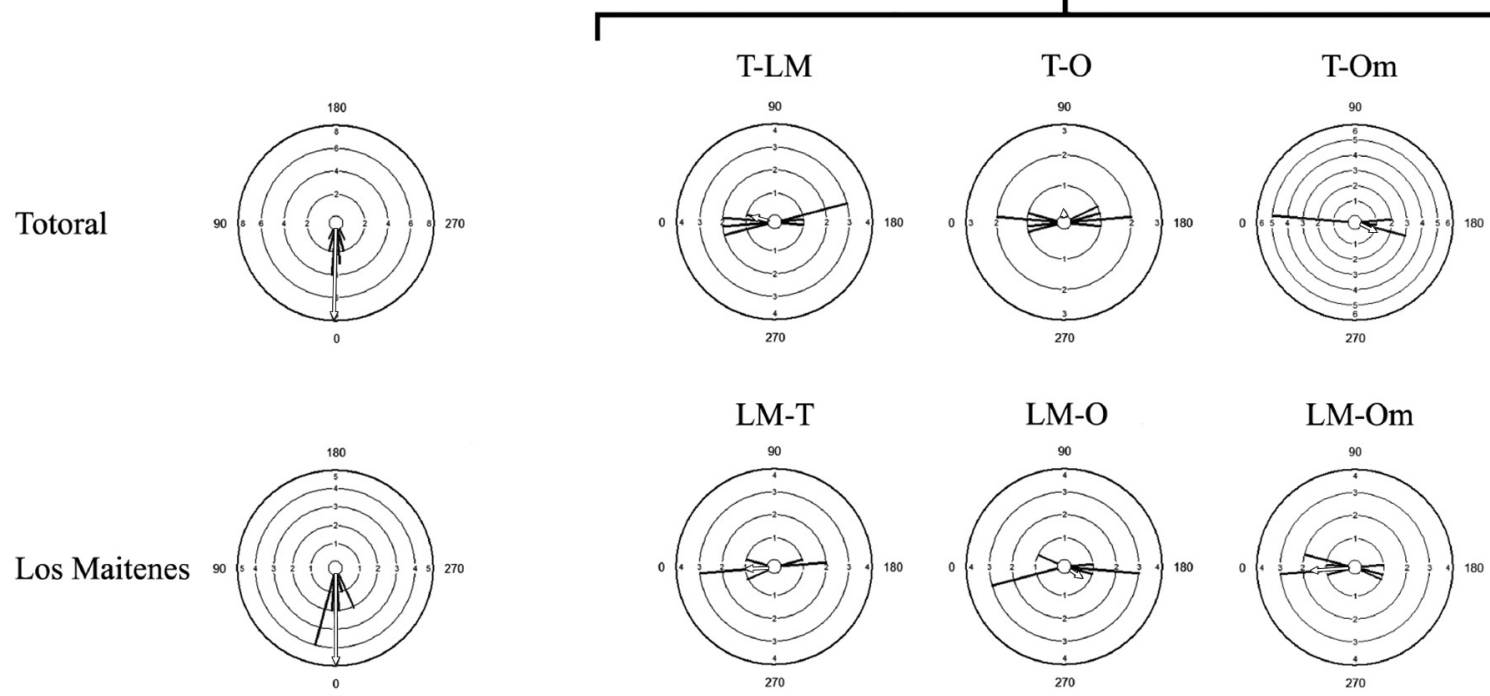

O-LM
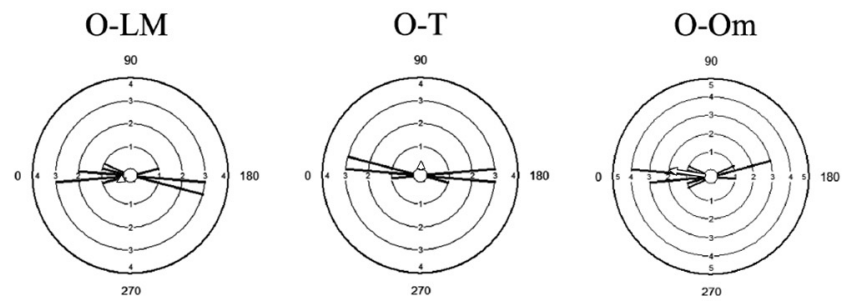

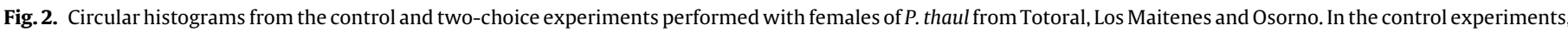

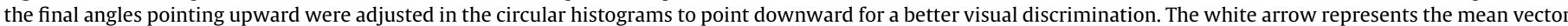

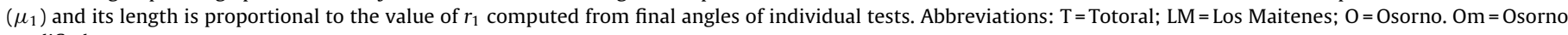
modified.

\subsection{Two-choice experiments}

Females that showed a positive response in the control experiment were subjected to the two-choice experiments. In each locality, two-choice experiments presenting the local synthetic call, the calls of the other two populations and the Osorno modified call were performed. The procedures followed for these experiments were similar to those for the control experiments, namely females were placed at the center of arena under the inverted strainer for $1 \mathrm{~min}$, time during which subjects from Totoral and Osorno were exposed to local chorus noise. Subsequently, the stimuli were broadcast via the test loudspeakers. In these experiments, two-choice tests between the local standard and standard calls of the two foreign localities were carried out. In addition, a third twochoice test between the local standard call and the Osorno modified call corresponding to each locality was conducted. For instance, experiments performed with every female from the Totoral population were as follows: T-LM, T-O and T-Om. The two stimuli were presented from different test loudspeakers in an alternate mode, and the silent interval between successive presentations of each stimulus corresponded to an interval doubling the duration of the longer stimulus presented in a given two-choice test. For a given female, the local standard call was broadcast from any of the two test loudspeakers chosen at random before starting the test, to avoid biases for loudspeaker or position. After $1 \mathrm{~min}$ of presentation of the stimuli we removed the inverted strainer, allowing the female to exert its choice. Response criteria were the same as those used in the control experiments. We measured body weight (Acculab, Pocket Pro, Newton, PA, USA; $\pm 0.01 \mathrm{~g}$ ) and SVL (Snout-Vent Length; Traceable Digital Caliper $\pm 0.03 \mathrm{~mm}$ ) for all females sub- jected to two-choice experiments. Each female was subjected to all tests during the same night with one-hour intervals between successive tests. Due to technical problems, we did not complete the three two-choice experiments for one subject from Osorno, which was not subjected to the Osorno-Los Maitenes and Osorno-Totoral tests.

\subsection{Recording and analysis of phonotactic responses}

Female phonotactic responses in the control and two-choice experiments were video-recorded with a camcorder (miniDV SONY DCR-HC48) placed at $2.5 \mathrm{~m}$ height from the center of the experimental arena. Recordings were carried out in darkness, only illuminated with a LED infrared light bulb placed at the same height of the camera. Videos were stored in miniDV tapes (Maxell ME DVM60SE and SONY ME DVM60) and acquired as AVI files on a MacBook 4.1 computer with iMovie 8.0 and Quicktime Player Pro 7.6. Phonotactic responses were analyzed off-line with a custommade routine on MATLAB 7.5 Software (MathWorks, Natick, MA, USA). This routine allowed us to perform a manual tracking of a subject position along its pathway in the experimental arena. From this tracking we extracted the following variables: "latency" to determine the time spent by the females in exerting a choice (time interval since the female leaves the center of the arena to arrival at the chosen loudspeaker), "route efficiency index" as a measure of the effectiveness of female displacement (REI, total distance traveled $/ 0.75 \mathrm{~m}$ ) and the "final angle" at which the females arrived relative to the loudspeaker broadcasting the local standard call (angle of final position relative to the loudspeaker). From the final angles obtained for all the individuals of a population for a 
given test we calculated the mean final angle $\left(\mu_{1}\right)$ and the length of the resulting vector $\left(r\right.$-statistics, $r_{1}$; Fig. 1 , Supplementary material). In addition to these measures, each tracked pathway was divided in 6 segments of equal length and the angle from the center of the arena to the end point of each segment was obtained. As such, for each pathway we obtained six descriptor angles of each female trajectory for all tests. From these six descriptor angles, we obtained a second mean final angle $\left(\mu_{2}\right)$ and r-statistics $\left(r_{2}\right)$. This provided us with an r-statistic for each segment (Fig. 1, Supplementary material). Together, these measures allowed us to assess the precision (i.e., REI, final angle, $\mu_{1}$ and $\mu_{2}$ ) and strength (i.e., latency, $r_{1}$ and $r_{2}$ ) of the female preferences.

In addition to the measures described, we counted the number of choices for each loudspeaker (i.e., local synthetic call or foreign synthetic call) in each test and within each population.

\subsection{Statistical analysis}

Kruskal-Wallis tests were used to compare latency, REI, $\mu_{2}$ and $r_{2}$ between control experiments of each locality. A Bonferroni correction was applied to all multiple comparisons and therefore the alpha calculated considered three multiple comparisons $(0.05 / 3=0.017)$. The same analysis was also used to compare weight and SVL of the subjects that showed positive responses in this test. We used one-tailed exact binomial test to determine if the probability of the number of preferences in response to the local synthetic call was higher relative to the foreign calls. In addition, we used Mann-Whitney $U$-tests $(\alpha=0.05)$ to compare both lineal (latency and REI) and circular $\left(r_{2}\right)$ parameters grouped by choice. All analyses were performed with Oriana 3.0 and STATISTICA 8.0 software for the circular and linear statistics, respectively.

\section{Results}

\subsection{Control experiment}

During control experiments, females of the three populations showed phonotactic responses to the standard stimulus of their population and no differences occurred among populations (Fig. 2). About half of the females tested responded to the standard stimulus of their own population ( 13 out of 34 females from Totoral, 11 out of 38 from Los Maitenes and 19 out of 41 from Osorno). Furthermore, $\mu_{2}(N=44, \mathrm{df}=2, H=1.0054, P=0.6049), r_{2}(N=44, \mathrm{df}=2, H=2.6748$, $P=0.2625)$ and REI $(N=44, \mathrm{df}=2, H=1.7166, P=0.4239)$ did not show significant differences among populations. However, the subjects showed significant differences in latency to reach the control loudspeaker among populations (latency: $N=44, \mathrm{df}=2, H=8.77$, $P=0.0124)$. Females from Los Maitenes spent shorter time to reach the control loudspeaker than the Osorno females $(P=0.0147)$ and the Totoral females showed intermediate latency values but did
Table 2

Number of females from three populations of $P$. thaul displaying phonotactic preferences for local or foreign synthetic calls. For one Osorno female, two experiments were not carried out (Osorno-Los Maitenes and Osorno-Totoral tests). Abbreviations: $\mathrm{T}=$ Totoral, $\mathrm{LM}=$ Los Maitenes, $\mathrm{O}=$ Osorno, $\mathrm{Om}=$ Osorno modified, $\mathrm{L}=$ Local synthetic call, $\mathrm{F}=$ Foreign synthetic call, $\mathrm{NR}=$ No response.

\begin{tabular}{llrlll}
\hline Population & Test & L & F & NR & P \\
\hline T & Control & 13 & & & \\
& T-LM & 7 & 5 & 1 & 0.3872 \\
T-O & 5 & 5 & 3 & 0.6230 \\
L M & 5 & 7 & 1 & 0.3872 \\
& Control & 11 & & & \\
& LM-T & 5 & 3 & 3 & 0.3633 \\
LM-O & 4 & 5 & 2 & 0.5000 \\
OM & 7 & 3 & 1 & 0.1719 \\
& Control & 19 & & & \\
& O-LM & 7 & 7 & 4 & 0.6047 \\
O-T & 7 & 7 & 4 & 0.6047 \\
& O-Om & 11 & 5 & 2 & 0.1051 \\
\hline
\end{tabular}

Ps for one-tailed exact Binomial tests.

not differ significantly from the other two populations (T-LM: $P=1.000 ; \mathrm{T}-\mathrm{O}=0.1681$ ).

Weight and SVL of the females differed between populations (Weight, $N=44, \quad \mathrm{df}=2, \quad H=36.10, \quad P<0.0001$; SVL, $N=44, \quad \mathrm{df}=2, \quad H=35.19, \quad P<0.0001) . \quad$ The Osorno females (Weight $=11.41 \pm 13.17 \mathrm{~g} ; \quad \mathrm{SVL}=49.76 \pm 9.76 \mathrm{~mm}$; average $\pm \mathrm{SD})$ were larger than both females from Totoral (Weight $=2.64 \pm 0.64 \mathrm{~g}$; $\mathrm{SVL}=29.46 \pm 4.17 \mathrm{~mm}$ ) and Los Maitenes (Weight $=4.24 \pm 0.74 \mathrm{~g}$; $\mathrm{SVL}=34.89 \pm 2.57 \mathrm{~mm}$ ) (Weight, $P<0.0001$ and $P=0.0023$; SVL, $P<0.0001$ and $P=0.0014$, respectively) and females from the last two populations did not differ significantly (Weight, $P=0.1285$; SVL, $P=0.2223$ ).

\subsection{Two-choice experiments}

Numbers of subjects choosing the local or foreign stimuli were similar among the three populations (Table 2, Fig. 2). In choice experiments no differences occurred either when pooling all local and foreign choices obtained in the tests conducted for the three populations; 58 choices of local stimuli out of 105 tests were obtained (one-tailed Binomial test: $P=0.1646$ ). Latencies to respond were also similar between most of the choices, with the exceptions of the Osorno population for the O-LM test in which the subjects responded with shorter latencies to the foreign. In addition, the latency to respond to the Om stimulus was shorter than to the local stimulus and this difference was marginally significant (Table 3). The REIs were similar for all choices in the three populations (Table 4 ). Mean vectors $\left(\mu_{1}\right)$ and lengths of mean vectors $\left(r_{1}\right)$ calculated from final angles were low for all tests. In Totoral, mean vector of T-LM test was directed to the local loudspeaker whereas in $\mathrm{T}-\mathrm{Om}$ test pointed to the foreign

Table 3

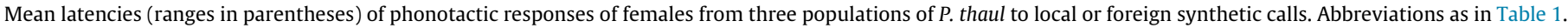

\begin{tabular}{|c|c|c|c|c|c|}
\hline Population & Test & $\mathrm{L}(\mathrm{s})$ & $\mathrm{F}(\mathrm{s})$ & $\mathrm{Z}$ & $\mathrm{P}$ \\
\hline \multirow[t]{4}{*}{ Totoral } & Control & $152.5(43-339)$ & & & \\
\hline & T-LM & $173.1(36-263)$ & $200.8(80-439)$ & 0.0812 & 0.9353 \\
\hline & $\mathrm{T}-\mathrm{O}$ & $202.8(99-480)$ & $155(29-404)$ & 0.5222 & 0.6015 \\
\hline & $\mathrm{T}-\mathrm{Om}$ & $173.4(68-280)$ & $116.1(35-277)$ & 1.5428 & 0.1229 \\
\hline \multirow[t]{4}{*}{ Los Maitenes } & Control & $111.6(7-254)$ & & & \\
\hline & LM-T & $153(17-525)$ & $102(93-118)$ & -0.4472 & 0.6547 \\
\hline & LM-O & $230.8(65-402)$ & $120(48-231)$ & 1.2248 & 0.2206 \\
\hline & LM-Om & $163(14-373)$ & $180(67-317)$ & -0.5698 & 0.5688 \\
\hline \multirow[t]{4}{*}{ Osorno } & Control & $231.1(64-555)$ & & & \\
\hline & O-LM & $274.9(93-587)$ & $133.9(63-292)$ & 2.1988 & 0.0279 \\
\hline & $\mathrm{O}-\mathrm{T}$ & $176.3(68-392)$ & $234.9(98-387)$ & -1.2139 & 0.2248 \\
\hline & $\mathrm{O}-\mathrm{Om}$ & $252.1(26-420)$ & $137.4(68-323)$ & 1.9259 & 0.0541 \\
\hline
\end{tabular}

Ps for Mann-Whitney $U$-tests. 
Table 4

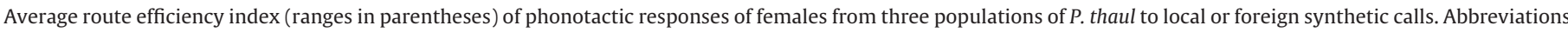
as in Table 1.

\begin{tabular}{|c|c|c|c|c|c|}
\hline Population & Test & $\mathrm{L}(\mathrm{s})$ & $\mathrm{F}(\mathrm{s})$ & $\mathrm{Z}$ & $\mathrm{P}$ \\
\hline \multirow[t]{4}{*}{ Totoral } & Control & $1.86(0.88-3.59)$ & & & \\
\hline & T-LM & $1.91(1.07-3.53)$ & $1.73(1.01-2.64)$ & 0.1624 & 0.8710 \\
\hline & $\mathrm{T}-\mathrm{O}$ & $2.26(1.04-4.06)$ & $1.71(0.96-2.75)$ & 0.7311 & 0.4647 \\
\hline & $\mathrm{T}-\mathrm{Om}$ & $1.42(1.03-2.17)$ & $1.56(0.99-3.41)$ & 0.3248 & 0.7453 \\
\hline \multirow[t]{4}{*}{ Los Maitenes } & Control & $1.94(0.91-3.85)$ & & & \\
\hline & LM-T & $1.70(0.99-3.79)$ & $1.92(1.27-2.30)$ & -1.044 & 0.2967 \\
\hline & LM-O & $2.03(1.00-3.19)$ & $1.85(1.00-3.57)$ & 0.3674 & 0.7133 \\
\hline & $\mathrm{LM}-\mathrm{Om}$ & $1.70(1.05-3.53)$ & $1.29(0.97-1.56)$ & 0.5698 & 0.5688 \\
\hline \multirow[t]{4}{*}{ Osorno } & Control & $2.46(1.09-5.63)$ & & & \\
\hline & O-LM & $1.96(1.08-3.05)$ & $1.40(0.94-2.50)$ & 1.6202 & 0.1052 \\
\hline & $\mathrm{O}-\mathrm{T}$ & $1.69(1.09-3.69)$ & $2.48(1.00-4.27)$ & -1.214 & 0.2248 \\
\hline & $\mathrm{O}-\mathrm{Om}$ & $2.59(1.06-7.34)$ & $1.34(1.11-1.86)$ & 0.963 & 0.3356 \\
\hline
\end{tabular}

Ps for Mann-Whitney $U$-tests.

Table 5

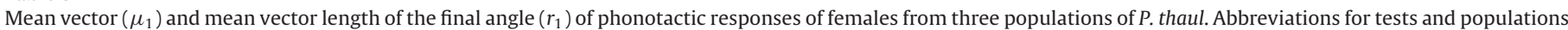
as in Table $1 . \mathrm{L}=$ Local loudspeaker. $\mathrm{NR}=$ No response. $\mathrm{F}=$ Foreign loudspeaker.

\begin{tabular}{|c|c|c|c|c|}
\hline Population & Test & Mean vector $\left(\mu_{1}\right)$ & Total choice & Length of mean vector $\left(r_{1}\right)$ \\
\hline \multirow[t]{4}{*}{ Totoral } & Control & 1.129 & $\mathrm{~L}$ & 0.978 \\
\hline & T-LM & 12.815 & $\mathrm{~L}$ & 0.171 \\
\hline & $\mathrm{T}-\mathrm{O}$ & 89.420 & NR & 0.053 \\
\hline & $\mathrm{T}-\mathrm{Om}$ & 202.101 & $\mathrm{~F}$ & 0.166 \\
\hline \multirow[t]{4}{*}{ Los Maitenes } & Control & 359.78 & $\mathrm{~L}$ & 0.974 \\
\hline & LM-T & 355.954 & $\mathrm{~L}$ & 0.243 \\
\hline & LM-O & 211.542 & $\mathrm{~F}$ & 0.145 \\
\hline & LM-Om & 356.190 & $\mathrm{~L}$ & 0.400 \\
\hline \multirow[t]{4}{*}{ Osorno } & Control & 357.918 & $\mathrm{~L}$ & 0.974 \\
\hline & O-LM & 336.097 & $\mathrm{~L}$ & 0.072 \\
\hline & $\mathrm{O}-\mathrm{T}$ & 94.551 & NR & 0.061 \\
\hline & $\mathrm{O}-\mathrm{Om}$ & 10.321 & $\mathrm{~L}$ & 0.379 \\
\hline
\end{tabular}

loudspeaker. T-O test showed an intermediate direction between the two loudspeakers (Fig. 2). In Los Maitenes, both LM-T and LM-Om tests showed mean vectors directed to the local loudspeaker, in contrast to LM-Om test in which the mean vector pointed to the foreign loudspeaker. Finally, in Osorno, both O-LM and $\mathrm{O}-\mathrm{Om}$ tests showed mean vectors pointing to the local loudspeaker while the mean vector had an intermediate direction in the $\mathrm{O}-\mathrm{T}$ test. Length of mean vectors $\left(r_{1}\right)$ was low for all tests performed in the three populations (Table 5 and Fig. 2). Furthermore, we assessed the length of mean vectors $\left(r_{2}\right)$ from segment partition of the route performed by each female. These length of mean vectors showed similar values between the choices performed by females in each test (Totoral, T-LM, $Z=0.7321, P=0.4641$; T-O, $Z=-1.1490, P=0.2506$; $\mathrm{T}-\mathrm{Om}, Z=0.0000, P=1.0000$. Los Maitenes, LM-T, $Z=0.4472, P=0.6547 ; \mathrm{LM}-\mathrm{O}, Z=0.7349, P=0.4624$; LM-Om, $Z=-1.0257, P=0.3051$. Osorno, $\mathrm{O}-\mathrm{LM}, Z=0.3472, P=0.7285 ; \mathrm{O}-\mathrm{T}$, $Z=0.0000, P=1.0000 ; 0-0 m, Z=-0.0566, P=0.9548)$.

\section{Discussion}

Overall, our study shows that $P$. thaul females had similar phonotactic preferences in responses to synthetic stimuli having acoustic structures of the advertisement calls from local or foreign location. The number of preferences and REI did not differ for all tests and for all populations. Five out of nine two-choice experiments yielded final angles pointing to the local loudspeaker, and the lengths of mean vectors $\left(r_{1}\right)$ were too low to consider these orientations as robust preferences.

Latency to respond was similar in all tests, with the exception of the discrimination of Osorno females between Osorno and Los Maitenes stimuli, in which latencies to respond were shorter for the Los Maitenes stimulus. Also for this population, the discrimina- tion between Osorno and Osorno modified stimuli yielded shorter latencies for the last stimulus that were marginally significant. It is possible that these differences are due the longer duration of the foreign stimuli presented.

It could be argued that the exposures of the experimental subjects to local chorus noise in Totoral and Osorno for one minute prior to phonotaxis tests could bias the females' preferences for the local call. However our results showing lack of preferences in these two populations indicate that no effect of this kind occurred. Furthermore, females from Los Maitenes which were not exposed to chorus noise exhibited a lack of preferences similar to those of the two other populations. Another methodological issue of potential relevance is that the cessation of exposure to chorus noise could have decreased female responsiveness as occurs with the vocal activity of males of the túngara frog Engystomops pustulosus following the offset of continuous chorus noise (Dapper et al., 2011). However, the females of Totoral and Osorno tested in our study continued to exhibit phonotactic responses after the cessation of chorus noise.

It is particularly notable that $P$. thaul females did not show preferences for stimuli having lower frequencies either. Anuran females of a number of species exert preferences for frequencies lower than average dominant frequency of the advertisement calls of conspecific males (Márquez, 1995a,b Ryan et al., 1992). This response pattern could be determined by a tuning of the auditory system of females to frequencies lower than the average dominant frequency of male advertisement calls (Gerhardt and Schwartz, 2001; Ryan et al., 1992; Ryan and Keddy-Hector, 1992). According to this tendency, females from Los Maitenes could have been expected to respond preferentially to the call of Totoral, since this signal has a similar temporal structure to the call of Los Maitenes, but a lower dominant frequency. 
Our results show that $P$. thaul females display phonotactic responses to synthetic stimuli over a wide range of acoustic characteristics. These responses have been shown to depend on stimuli intensity in various anuran species (e.g., Gerhardt and Huber, 2002; Höbel and Gerhardt, 2003). It is probable that stimulation with lower intensities would have yielded differences in preferences in the populations of $P$. thaul analyzed. In males of this species, auditory and evoked vocal responses thresholds are very similar (Penna et al., 2008), and it is probable that females have similar thresholds. Females of various species also show a close correspondence between auditory and phonotactic response thresholds (Beckers and Schul, 2004; Gerhardt and Klump, 1988; Lombard and Straughan, 1974). If females of $P$. thaul exhibit a similar close correspondence between neural and behavioral responses, we would expect them to be less selective when they are subjected to phonotactic tests with local and foreign stimuli because they will respond similarly to any stimulus having intensity well above their auditory thresholds.

The lack of phonotactic preferences by $P$. thaul females is a condition similar to the one reported in the Asian planthopper, Nilaparvata bakeri, in which acoustic signals emitted by males vary across an extensive geographic area (Philippines, Indonesia, India and Sri Lanka) in parameters as call length, pulse repetition frequency or number of characteristic call motives. However, females from both Philippines and Indonesia do not exhibit preferences between acoustic signals from origin and foreign localities (Claridge and Morgan, 1993). These results indicate that geographic variation of the acoustic signals produced by males does not necessarily operate as a prezygotic barrier promoting reproductive isolation and speciation. Similar lack of phonotactic preferences have been found at an inter-specific level in females of katydids of two species of the genus Neoconocephalus (Bush and Schul, 2010). Such lack of phonotactic preferences for local versus foreign calls by $P$. thaul females indicate that inter-sexual selection has not been a significant factor for the divergence of the advertisement call of this species.

These results showing a lack of variation in phonotactic responses in two-choice experiments contrast with a previous study which showed a notable variation of the evoked vocal responses of males of this species from the same populations and using the same stimuli as in the current study (Velásquez et al., 2014) (see Fig. 3). In that study males from Totoral and Los Maitenes respond with lower number of pulses to the call of Osorno as compared to the calls of the other two populations. The low vocal responses to the Osorno call were related to a high sensitivity of males of these populations to changes in the depth of intra-pulse amplitude modulation in the calls. Since Osorno calls have low modulation depths relative to the calls of the northern and central populations, males from Totoral and Los Maitenes responded with a low vocal activity to these stimuli. In addition, males of Osorno responded with a low number of pulses to the local call relative to Totoral and Los Maitenes calls. This response pattern is related to the high sensitivity of Osorno males to variations in the number of pulses of the stimuli. The Osorno call has a low number of pulses, and males from this population respond with relative low vocal activity to the local stimulus. In short, the geographic variation in the patterns of vocal responses of males suggests that the different vocal interactions occurring in each population are relevant for the evolution of signals and sound communication system of this extensively distributed frog.

In contrast with the above described results on male vocal responses, the present study indicates that females show no substantial differences in the strength of their phonotactic responses to any local or foreign stimuli. It has been reported that the female preferences for acoustic signals can be affected by the background noise environment in which animals communicate (Wollerman and Wiley, 2001; Wong and Candolin, 2005). The three popula-
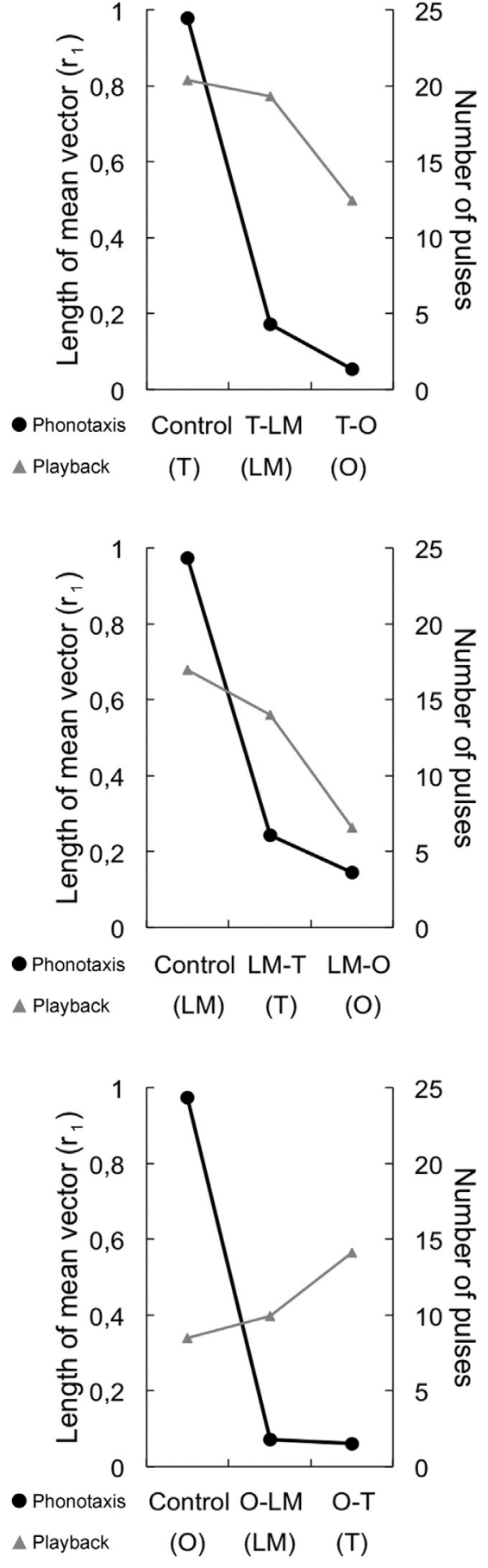

Fig. 3. Comparisons between the phonotactic responses of females from this study and male evoked vocal responses from playback experiments carried out in a former study (Velásquez et al., 2014) for the populations of (A) Totoral, (B) Los Maitenes and (C) Osorno. Black circles show the length of mean vector $\left(r_{1}\right)$ for two-choice phonotactic experiments considering local and foreign stimuli and gray triangles indicate differences between mean number of pulses (NP) in evoked vocal responses to playback experiments with local and foreign stimuli. Abbreviations as in Fig. 2.

tions considered in this study exert their chorusing and breeding activity in absence of other anuran species, and are therefore subjected only to conspecific chorusing background noise. Females from these three populations therefore are not subjected to the risk of heterospecific amplexus and associated hybridization. Taking into account these circumstances, it is possible that a loosening of the selective pressures for choosing a conspecific male of strictly defined vocal characteristics determine the lack of phonotaxis pref- 
erences observed. Along its extensive distribution, P. thaul shares environments with others anuran species as follow: Rhinella atacamensis and $R$. arunco in northern populations; $R$. spinulosa, $R$. arunco, Calyptocephallela gayi, Alsodes nodosus, Batrachyla taeniata and Eupsophus queulensis in central populations and C. gayi, B. taeniata, B. leptopus, $B$ antartandica, Hylorina sylvatica and several species of Eupsophus genus in the southern populations. However, some of these species emit just release calls (e.g. species of the Rhinella genus) and advertisement calls emitted by the other species are considerably different from the calls emitted by males of $P$. thaul (Penna and Veloso, 1990; Márquez et al., 2005 Opazo et al., 2009). Furthermore, no calling heterospecifics are observed in our study populations of $P$. thaul. Future experiments are necessary to establish with precision the effects of biotic noise of conspecific well as heterospecific origins on the phonotactic preferences of the females in this species.

Studies aimed at understanding how female responsiveness is known to depend on their stage in the reproductive cycle in some species: receptivity (response to a conspecific mate signal), permissiveness (response to a signal that is less attractive than conspecific signals) and discrimination (ability to discern signal differences) differ among pre, post and amplectic females of Engystomops pustulosus (Lynch et al., 2005), and this variability is related to reproductive hormone levels (Lynch et al., 2005). Also, motivation to respond by females of midwife toads Alytes is related to reproductive stage (Bosch et al., 2003). In contrast with this evidence, in females of the cricket frog Acris crepitans, responsiveness in phonotactic tests does not differ between amplectant and nonamplectant individuals (Witte et al., 2000). The subjects used in our study were all non-amplectant, and although there is no information on the precise stage of the reproductive cycle in which they were caught, the similar lack of phonotactic preferences in all populations are unlikely to depend on differences in the reproductive cycle within each population. Additional studies would allow to relate the stage of the reproductive cycle with receptivity, permissiveness and discrimination in each population of $P$. thaul and to identify hormonal and environmental factors affecting these response measures.

The remarkable variation of the advertisement calls along the extensive geographic distribution of $P$. thaul (Velásquez et al., 2013; Velásquez, 2014), the corresponding variation in the vocal responses of males (Velásquez et al., 2014), and the absence of preferences for call patterns by females of this species highlight the importance in this anuran of inter-male communication and the role of intra-sexual selection as a driving force in the evolution of the sound communication system, a process that has been proposed to operate in other vertebrates as well as in invertebrates (Byrne 2004; Endler et al., 2005; ten Cate et al., 2002; West-Eberhard, 1984).

\section{Acknowledgments}

We are grateful to Maricel Quispe, Daniel Zuñiga, Daniel Opazo, Jesus Marambio and Felipe Moreno who helped in the field activities. This study was supported by Fellowship for Doctoral thesis CONICYT AT24080118, Fellowship for Doctoral thesis from the Guillermo Puelma Foundation for Neurosciences and CONICYT/FONDECYT/POSTDOCTORADO N ${ }^{\circ} 3120208$ to NAV. Additional funding was provided by FONDECYT grant 1080459 to MP, ICMP05-002, PFB-23-CONICYT and FONDECYT grants 1090794 and 1140548 to RAV and ICM-P10-001-F to JLV. The procedures used in this study are approved by regulations for animal care and conservation in Chile (Livestock and Agriculture Service (SAG) permit number 1645 and 7311). We also thank Patrick Matzler for reviewing the manuscript.

\section{Appendix A. Supplementary data}

Supplementary data associated with this article can be found, in the online version, at http://dx.doi.org/10.1016/j.beproc.2015. 06.001

\section{References}

Andersson, M., 1994. Sexual Selection. Princeton University Press, Princeton. Beckers, O., Schul, J., 2004. Phonotaxis in Hyla versicolor (Anura: Hylidae): the effect of absolute call amplitude. J. Comp. Physiol. A 190, 869-876.

Bernal, X., Guarnizo, C., Luddecke, H., 2005. Geographic variation in advertisement call and genetic structure of Colostethus palmatus (Anura, Dendrobatidae) from the Colombian Andes. Herpetologica 61, 395-408.

Bosch, J., Márquez, R., Boyero, L., 2003. Behavioural patterns, preference, and motivation of female midwife toads during phonotaxis tests. J. Ethol. 21, 61-66

Boul, K.E., Funk, W.C., Darst, C.R., Cannatella, D.C., Ryan, M.J., 2007. Sexual selection drives speciation in an Amazonian frog. Proc. R. Soc. B 274, 399-406.

Bush, S.L., Schul, J., 2010. Evolution of novel signal traits in the absence of female preferences in Neoconocephalus Katydids (Orthoptera, Tettigoniidae). PLoS One 5, e12457.

Byrne, P.G., 2004. Intrasexual selection and group spawning in quacking frogs (Crinia georgiana). Behav. Ecol. 15, 872-882, http://dx.doi.org/10.1093/beheco/ arh100

Claridge, M.F., Morgan, J., 1993. Geographical variation in acoustic signals of the planthopper, Nilaparvata bakeri (Muir), in Asia: species recofnition and sexual selection. Biol. J. Linn. Soc. 48, 267-281.

Correa, C., Sallaberry, M., González, B.A., Soto, E.R., Mendez, M., 2007. Amphibia, Anura, Leiuperidae, Pleurodema thaul: latitudinal and altitudinal distribution extension in chile. Check List 3, 267-270.

Coyne, J.A., Orr, H.A., 2004. Speciation. Sinauer Associates Sunderland, MA.

Dapper, A.L., Baugh, A.T., Ryan, M.J., 2011. The sounds of silence as an alarm cue in túngara frogs, Physalaemus pustulosus. Biotropica 43, 380-385.

Darwin, C., 1871. The Descent of Man and Selection in Relation to Sex. John Murray, London.

Endler, J.A., Basolo, A.L., 1998. Sensory ecology, receiver biases and sexual selection. Trends Ecol. Evol. 13, 415-420.

Endler, J.A., Westcott, D.A., Madden, J.R., Robson, T., 2005. Animal visual systems and the evolution of color patterns: sensory processing illuminates signal evolution. Evolution 59, 1795-1818.

Gerhardt, H., Huber, F., 2002. Acoustic Communication in Insects and Anurans. University of Chicago Press, Chicago.

Gerhardt, H.C., Klump, G., 1988. Phonotactic responses and selectivity of barking treefrogs (Hyla gratiosa) to chorus sounds. J. Comp. Physiol. A 163, 795-802.

Gerhardt, H.C., Schwartz, J.J., 2001. Auditory tuning and frequency preferences. In: Ryan, M. (Ed.), Anuran Communication. Smithsonian Inst. Press, Washington.

Höbel, G., Gerhardt, C., 2003. Reproductive character displacement in the acoustic communication system of green tree frogs (Hyla cinerea). Evolution 57, 894-904.

Lombard, E., Straughan, I., 1974. Functional aspects of anuran middle ear structures. J. Exp. Biol. 61, 71-93.

Lynch, K.S., Rand, A.S., Ryan, M.J., Wilczynski, W., 2005. Plasticity in female mate choice associated with changing reproductive states. Anim. Behav. 69, 689-699.

Márquez, R., 1995a. Female choice in the midwife toads (Alytes obstetricans and $A$ cisternasii). Behaviour 132, 151-161.

Márquez, R., 1995b. Preferencia de las hembras por cantos de frecuencia dominante baja en el sapo partero común Alytes obstetricans (Anura, Discoglossidae). Experimentos in situ. Rev. Esp. Herp. 9, 77-83.

Nevo, E., Capranica, R., 1985. Evolutionary origin of ethological reproductive isolation in cricket frogs Acris. Evol. Biol. 19, 147-214.

Opazo, D., Velásquez, N., Veloso, A., Penna, M., 2009. Frequency-modulated vocalizations of Eupsophus queulensis (Anura: Cycloramphidae). J. Herpetol. 43, 657-664.

Penna, M., Veloso, A., 1990. Vocal diversity in frogs of the south american temperate forest. J. Herpetol. 24, 23-33.

Penna, M., Solís, R., 1998. Frog call intensities and sound propagation in the South American temperate forest region. Behav. Ecol. Sociobiol. 42, 371-381.

Penna, M., Velásquez, N., Solís, R., 2008. Correspondence between evoked vocal responses and auditory thresholds in Pleurodema thaul (Amphibia; Leptodactylidae). J. Comp. Physiol. A 194, 361-371.

Pröhl, H., Hagemann, S., Karsch, J., Höbel, G., 2007. Geographic variation in male sexual signals in strawberry poison frogs (Dendrobates pumilio). Ethology 113 825-837.

Pröhl, H., Koshy, R., Mueller, U., Rand, S., Ryan, M., 2006. Geographic variation of genetic and behavioral traits in northern and southern tungara frogs. Evolution 60, 1669-1679.

Ryan, M., Perrill, S., Wilczynski, W., 1992. Auditory tuning and call frequency predict population-based mating preferences in the cricket frog. Acris crepitans, Am. Nat. 139, 1370-1383.

Ryan, M.J., 1998. Sexual selection, receiver biases, and the evolution of sex differences. Science 281, 1999.

Ryan, M.J., Keddy-Hector, A.C., 1992. Directional patterns of female mate choice and the role of sensory biases. Am. Nat. 139, S4-S35. 
Searcy, W., Nowicki, S., 2009. Sexual selection and the evolution of animal signals. In: Squirre, L. (Ed.), Encyclopedia of Neuroscience. Academic Press, Oxford, pp. 769-776.

ten Cate, C., Slabbekoorn, H., Ballintijn, M., 2002. Birdsong and male-male competition: causes and consequences of vocal variability in the collared dove (Streptopelia decaocto). Adv. Stud. Behav. 31, 31-75.

Velásquez, N.A., 2014. Geographic variation in acoustic communication in anurans and its neuroethological implications. J. Physiol. Paris 108, 167-173.

Velásquez, N.A., Marambio, J., Brunetti, E., Méndez, M.A., Vásquez, R.A., Penna, M., 2013. Bioacoustic and genetic divergence in a frog with a wide geographical distribution. Biol. J. Linn. Soc. 110, 142-155.

Velásquez, N.A., Opazo, D., Díaz, J., Penna, M., 2014. Divergence of acoustic signals in a widely distributed frog: relevance of inter-male interactions. PLoS One 9 , e87732.

Veloso, A., 2006. Batracios de las cuencas hidrográficas de chile: origen, diversidad y estado de conservación. In: Vila, I., Veloso, A., Schlatter, R., Ramírez, C. (Eds.), Macrófitas y vertebrados de los sistemas límnicos de Chile. Editorial

Universitaria, Santiago, pp. 103-140.
West-Eberhard, M.J., 1984. Sexual selection, competitive communication and species specific signals in insects. In: Lewis, T. (Ed.), Insect Communication. New York Academic Press, New York, pp. 283-324.

Wilczynski, W., Ryan, M., 1999. Geographic Variation in Animal Communication System. Oxford University Press, Oxford, pp. 234-261.

Witte, K., Chen, K.-C., Wilczynski, W., Ryan, M.J., 2000. Influence of amplexus on phonotaxis in the cricket frog Acris crepitans blanchardi. Copeia 2000 257-261.

Wollerman, L., Wiley, R.H., 2001. Background noise from a natural chorus alters female discrimination of male calls in a Neotropical frog. Anim. Behav. 62, $1-8$.

Wong, B.B.M., Candolin, U., 2005. How is female mate choice affected by male competition? Biol. Rev. 80, 559. 